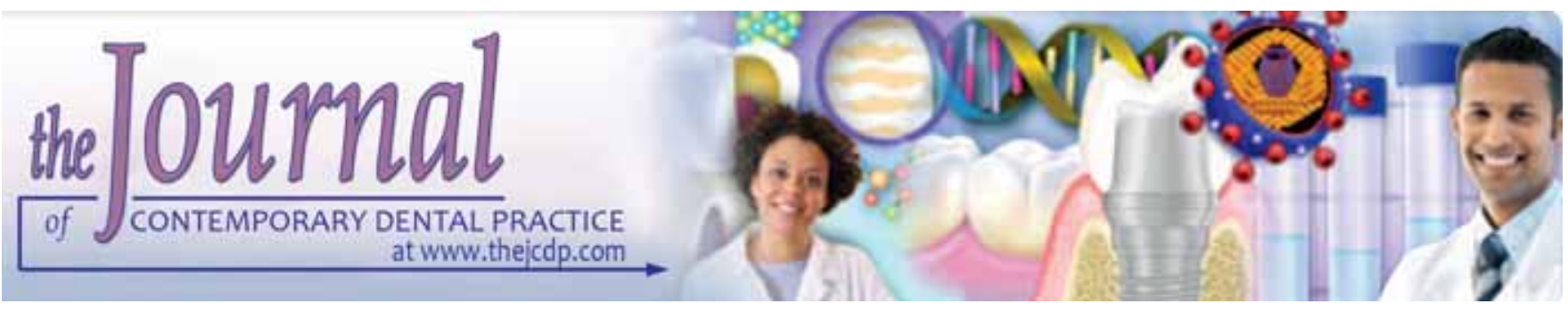

\title{
The Effect of Fiber Reinforcement on the Dimensional Changes of Poly Methyl Methacrylate Resin after Processing and after Immersion in Water: An in vitro Study
}

\author{
LM Ranganath, Ravindra Ganguly Keshav Shet, Rajesh AG, Sathish Abraham
}

\begin{abstract}
Aims and objectives: To evaluate and compare the effect of fiber reinforcement on the dimensional changes of heat-cured poly (methyl methacrylate) resin after processing and immersion in water.
\end{abstract}

Materials and methods: Three different heat-cure resins were selected for the present study: (1) Nonreinforced heat-cure methyl methacrylate resin, (2) High Impact heat-cured methyl methacrylate resin and (3) Fiberglass reinforced methyl methacrylate resin. Ninety samples were prepared using three different resins and denture bases obtained for the same. The amount of space between the tissue surface and the cast in the anterior, middle and posterior regions is measured after processing and immersion in water for 17 days using a traveling microscope having a least count of $0.001 \mathrm{~cm}$.

Results: Mean and standard deviation were calculated for the dimensional changes and were subjected to statistical analysis (Student t-test, unpaired). Among the three groups of resins, fiber reinforced heat-cured methyl methacrylate resin was found to be statistically highly significant in terms of dimensional changes when compared with the nonreinforced and high impact heat-cured resins.

Conclusion: Dimensional changes were evident in all the planes in the three groups studied and were in the following decreasing order-fiberglass reinforced heat-cured poly (methyl methacrylate) resin, high impact heat-cured poly (methyl methacrylate) resin and nonreinforced heat-cured poly (methyl methacrylate) resin.

Clinical significance: The fibers are added in order to increase the strength of acrylic resin. Considering only the strength may in turn affect the dimensional accuracy of the acrylic resin resulting in loss of retention and stability, affecting the fit of the denture.

Keywords: Methacrylate, Denture base, Denture retention, Fiber reinforced heat-cured resin.

How to cite this article: Ranganath LM, Shet RGK, AG Rajesh, Abraham S. The Effect of Fiber Reinforcement on the Dimensional Changes of Poly Methyl Methacrylate Resin after
Processing and after Immersion in Water: An in vitro Study. J Contemp Dent Pract 2011;12(4):305-317.

Source of support: Nil

Conflict of interest: None declared

\section{INTRODUCTION}

Poly (methyl methacrylate) is the resin most commonly used as a denture base material for the past 6 decades. This has remained the denture base material of choice although various polymers have been developed and introduced in dentistry to overcome the deficiencies of poly (methyl methacrylate) resin. This can be attributed to the fact that though the properties of poly (methyl methacrylate) resin are not ideal in every aspect, it is the combination of various rather than one single desirable property that accounts for their popularity and universal use. ${ }^{1}$

Various investigations have shown that the limitation of heat-cured poly (methyl methacrylate) resin in respect of strength, particularly under impact and fatigue conditions. ${ }^{2}$ Though the liability of the denture to fracture may be minimized by proper attention to denture design and its fabrication, the use of an alternative material with considerably improved strength which would resist fracture would be a great advantage. ${ }^{3,4}$

In recent years, the advances in polymer technology have produced other polymers such as high impact resins and fiber reinforced resins with improved impact strength and fatigue resistance. ${ }^{4-7}$

Though the incorporation of fillers like rubber and fibers to heat-cured poly (methyl methacrylate) resin improves the impact strength and fatigue resistance, it may affect some of the properties of heat-cured poly (methyl methacrylate) 
resin such as dimensional accuracy, dimensional stability and the effect of water sorption. ${ }^{8}$

Various investigators have compared the dimensional changes between different denture base materials, ${ }^{6-8,10}$ palatal vault configurations ${ }^{12}$ methods of packing, ${ }^{8-15}$ modes of polymerization ${ }^{2,17-26}$ and curing cycles. ${ }^{10,16}$ The works of these investigators showed that there were definite dimensional changes of varying magnitude occurring in heat-cured poly (methyl methacrylate) resin.

\section{AIMS AND OBJECTIVES}

1. To evaluate the effect of fiber reinforcement on the dimensional changes of heat-cured poly (methyl methacrylate) resin.

2. Comparative evaluation of the dimensional changes between nonreinforced, high impact and fiberglass reinforced heat-cured poly (methyl methacrtylate) resins after processing.

3. Comparative evaluation of the dimensional changes between nonreinforced, high impact and fiberglass reinforced heat-cured poly (methyl methacrylate) resins after immersion in water.

\section{MATERIALS AND METHODS}

To evaluate the effect of fiber reinforcement on the dimensional changes of heat-cured poly (methyl methacrylate) resin and to compare the dimensional changes in three types of heat-cured poly (methyl methacrylate) resins:

1. Nonreinforced heat-cured poly (methyl methacrylate) resin.

2. High impact heat-cured poly (methyl methacrylate) resin.

3. Fiberglass reinforced heat-cured poly (methyl methacrylate) resin.

After processing and after immersion in water were carried out in the Department of Prosthodontics, SDM College of Dental Sciences, Dharwad and Department of Physics, SDM College of Engineering, Dharwad.

The following armamentarium and materials were used for the study (Fig. 1):

1. Maxillary edentulous rubber mold (Columbia Dentoform, Columbia Dentoform Corporation, NY, USA).

2. Electronic weigh balance (Avery India Ltd, Ballabgarh, India) (Fig. 3).

3. Dental stone (Kalstone, Kalabhai Karson Pvt Ltd, Mumbai, India).

4. Vibrator (KAVO, EWL, West Germany).

5. Polystyrene sheets (Buffalo Dental Mfg. Co. Inc., NY, USA).
6. Sta-press Pressure Unit (Buffalo Dental Mfg. Co. Inc., NY, USA) (Fig. 6).

7. Modelling wax (The Hindustan dental products, Hyderabad, India).

8. Diamond disc (Dentaurum, Germany).

9. Travelling microscope (INCO, Ambala, India).

10. Dental flasks and clamps.

11. Dental plaster (Everest, M/S Panade Industries, Karnataka, India).

12. Nonreinforced heat-cured poly (methyl methacrylate) resin (Stellon, Dental products of India Ltd, Mumbai, India).

13. High impact heat-cured poly (methyl methycrylate) resin (Trevalon, Dentsply India Pvt. Ltd, New Delhi, India).

14. Fibers glass reinforced heat-cured poly (methyl methacrylate resin Polydent, Polydent products, Gujarat, India).

15. Hydraulic press (KAVO, EWL, West Germany).

16. Acrylizer (KAVO, EWL, West Germany).

The samples for the maxillary edentulous rubber mold (Fig. 2), ninety casts (Fig. 5) were prepared with dental stone using same water: Powder ratio (0.30), mixing time

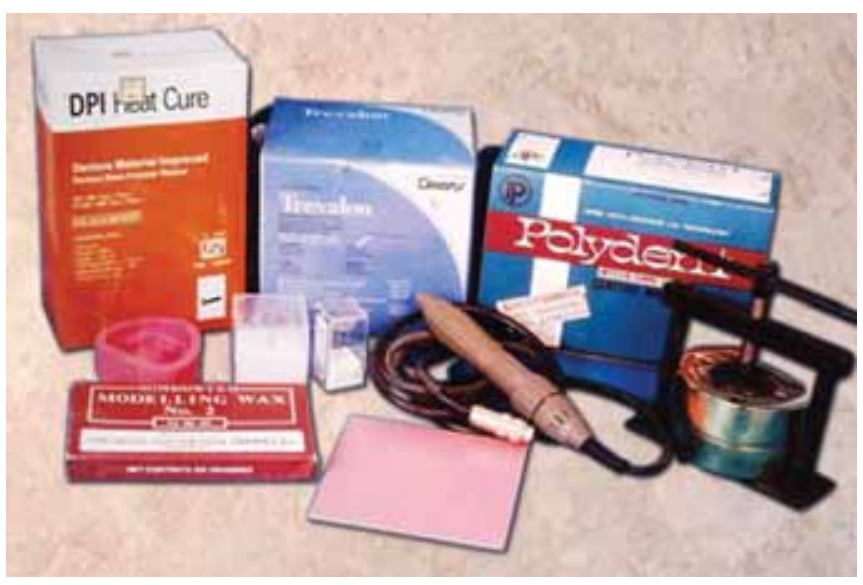

Fig. 1: Armamentarium

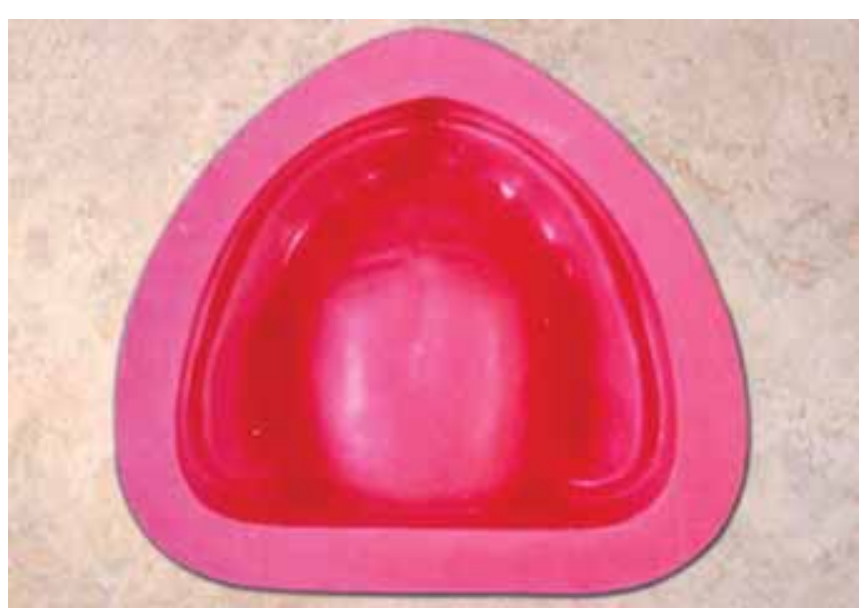

Fig. 2: Maxillary edentulous rubber mold 
(40 seconds) as well as use of vibrator (Fig. 4) till the mold was filled to ensure that all the obtained casts were fairy uniform.

Temporary denture bases were fabricated on all the ninety casts using polystyrene sheets, $2 \mathrm{~mm}$ thick in a stapress pressure unit at 30 pounds per square inch (psi). The temporary denture bases were numbered as follows (Fig. 7):

1. Group ' $S$ ' represents nonreinforced heat-cured poly (methyl methacrylate) resin.

2. Group ' $\mathrm{T}$ ' represents high impact heat-cured poly (methy1 methacrylate) resin.

3. Group ' $\mathrm{P}$ ' represents fiberglass reinforced heat-cured poly (methyl methacrylate) resin.

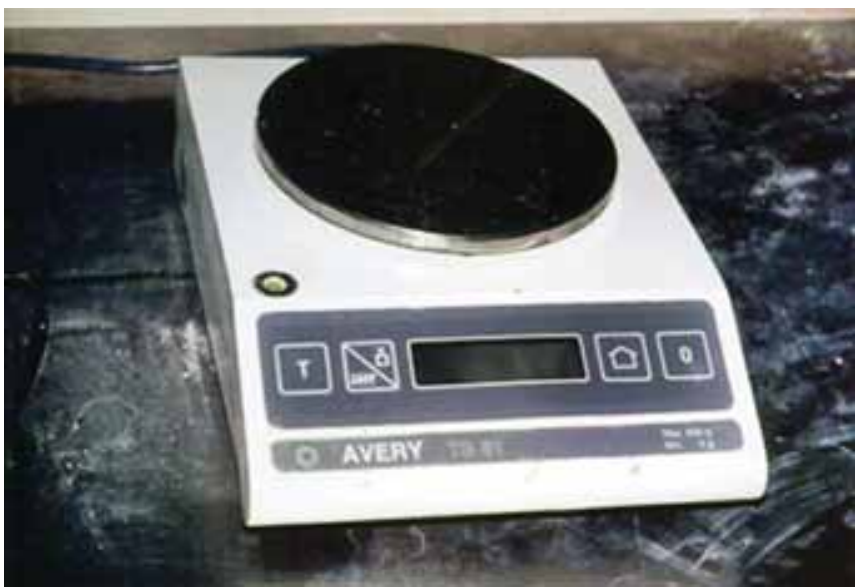

Fig. 3: Electronic weigh balance

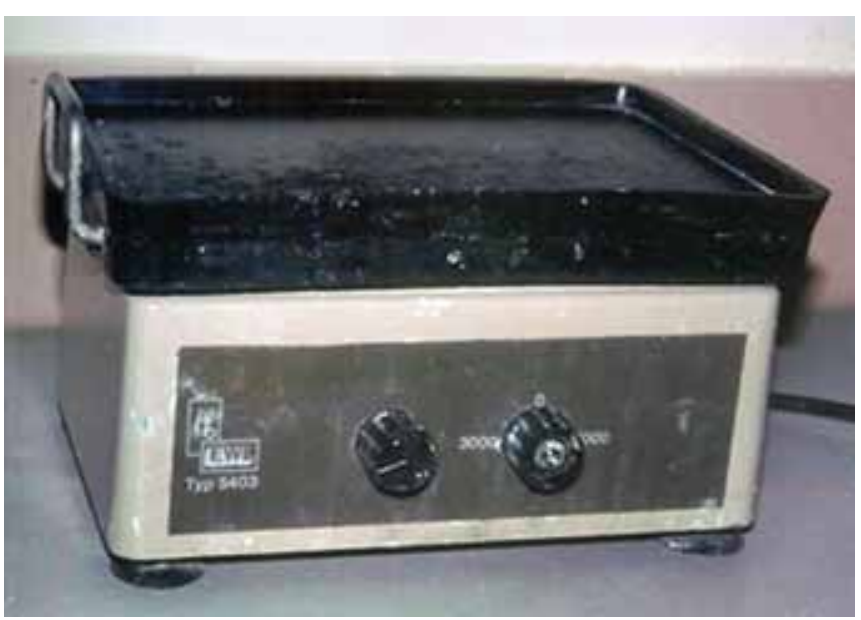

Fig. 4: Vibrator

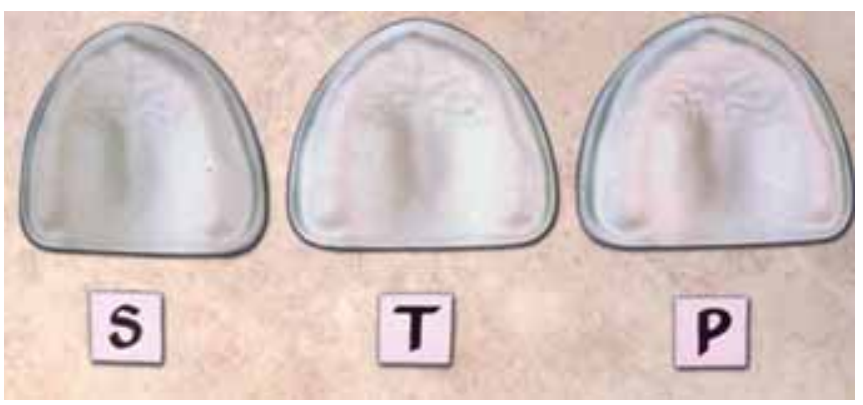

Fig. 5: Dental stone cast

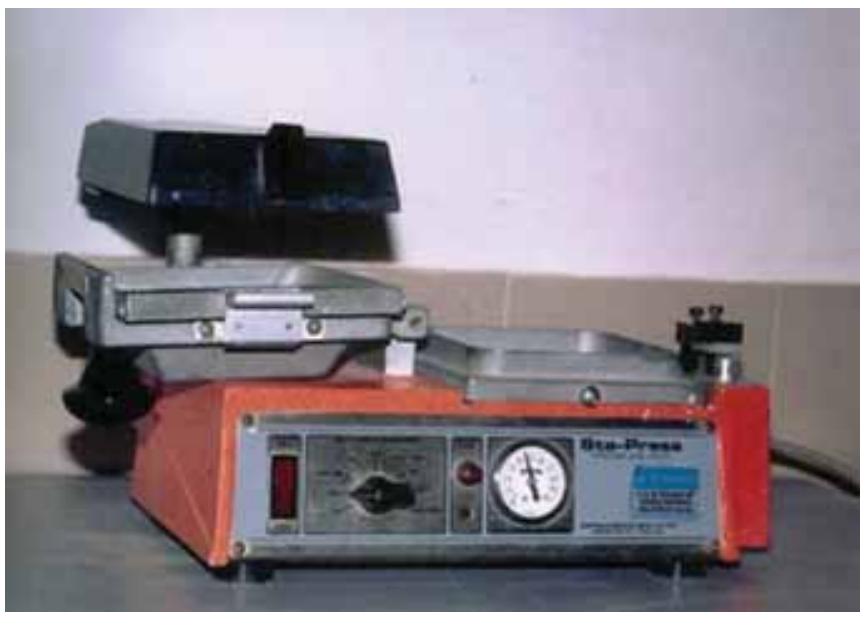

Fig. 6: Sta-press pressure unit

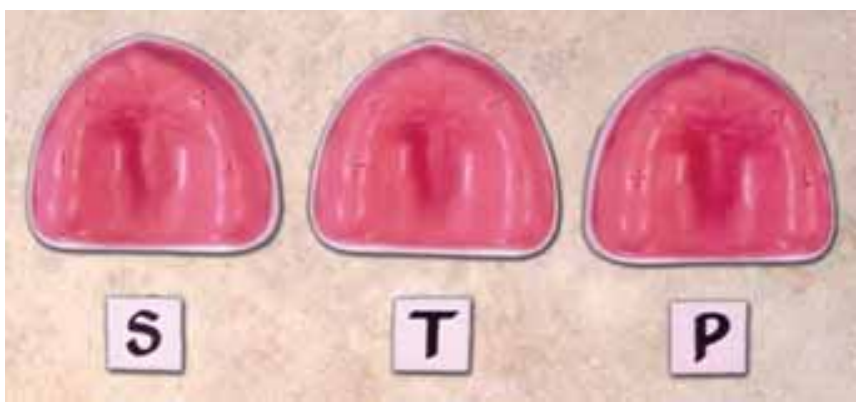

Fig. 7: Temporary denture bases

Among each group, casts and denture bases were numbered from 1 to 30.

Example:

S1, S2, S3, S4 .............

T1, T2, T3, T4

P1, P2, P3, P4

Reference marks in the form of cross lines were on all the temporary denture bases with a thin diamond disk in the region of canine and second molar on right and left sides (Figs 8 and 9). Upper right hand corner of the cross line was taken as the standard reference point for subsequent measurements. The distance from canine, second molar and canine to second molar region on right and left sides was measured on the temporary denture bases using a traveling microscope having a least count of $0.001 \mathrm{~cm}$ (Figs 10 and 11).

The temporary denture bases were invested in the cast half of the flask in dental plaster. The matrix half of the flask was filled with dental stone using same water: Powder ratio (0.30) and mixing time 40 sec.

After wax elimination, tin foil substitute, i.e. sodium alginate (DPI heat-cure cold mould seal, DPI, India for 'S' group, Dentsply heat-cure cold mould seal, Dentsply, India for ' $\mathrm{T}$ ' group and ISOLON concentrate cold mould seal, polydent products, India for ' $\mathrm{P}$ ' group) was applied to lukewarm dental plaster and dental stone surfaces. 


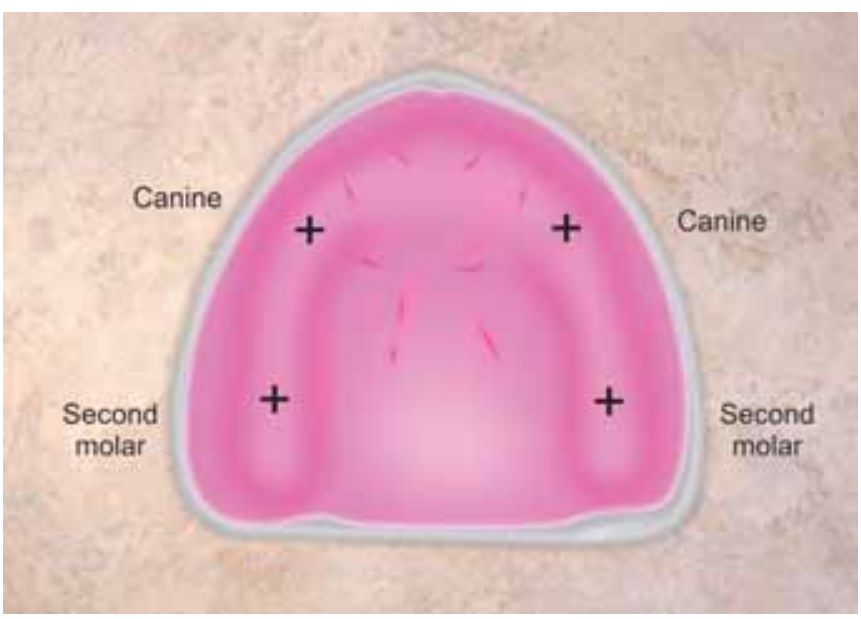

Fig. 8: Reference marks in the region of canine and second molar on right and left sides

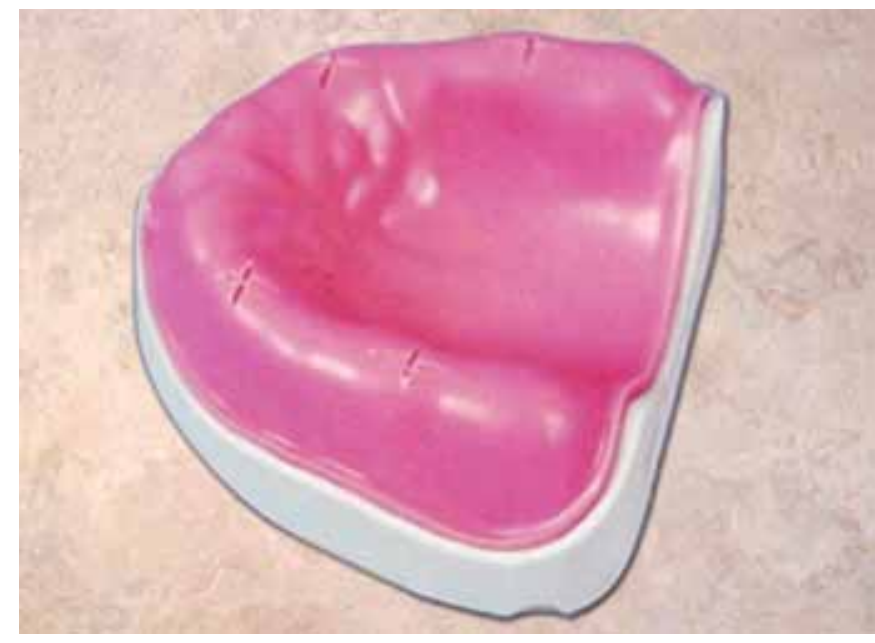

Fig. 9: Temporary denture base showing reference marks in the region of canine and second molar on right and left sides

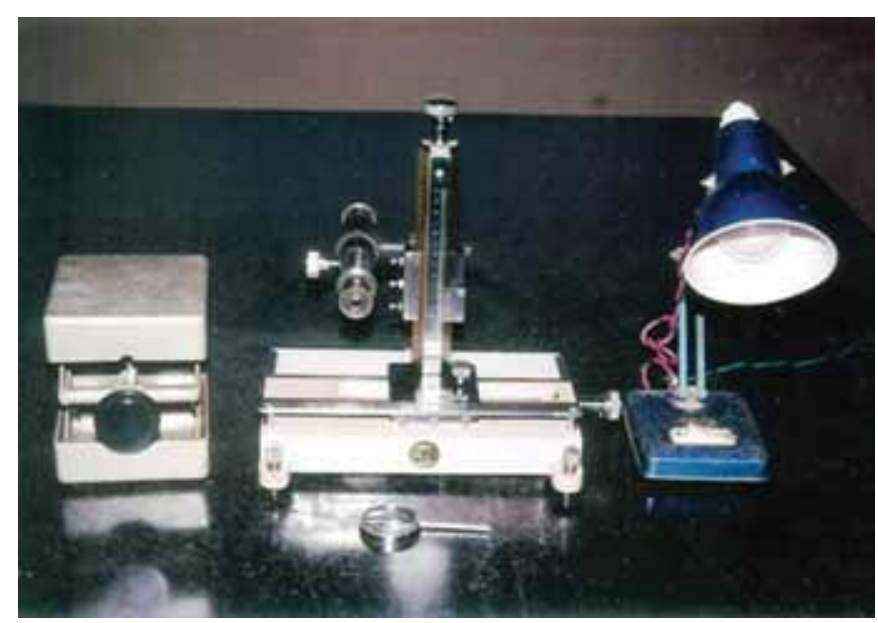

Fig. 10: Traveling microscope

Manufacturer's instructions were followed for proportioning and mixing monomer and polymer and polymer for each group of heat-cured poly (methyl methacrylate) resin. All the flasks were packed with dough

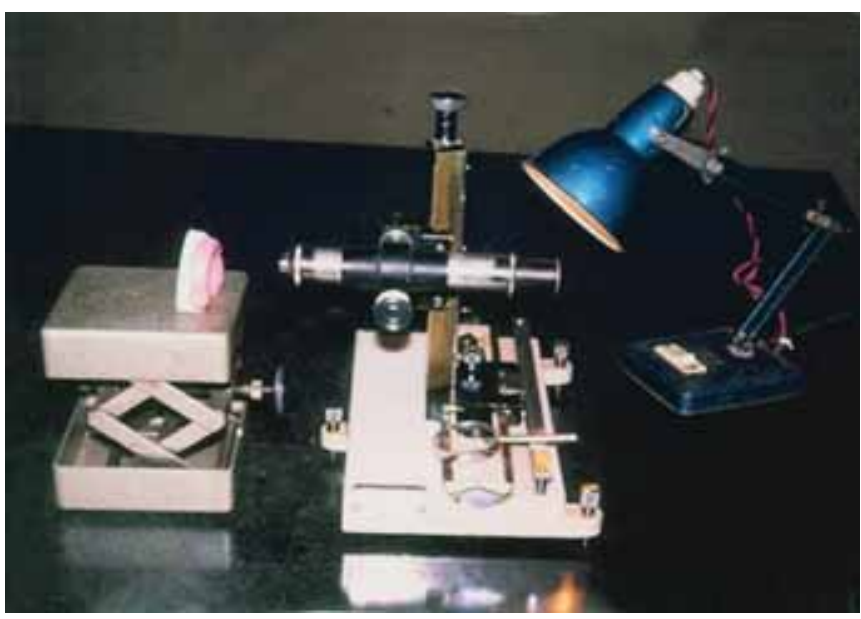

Fig. 11: Method used for measuring the distance between reference marks in the temporary denture bases

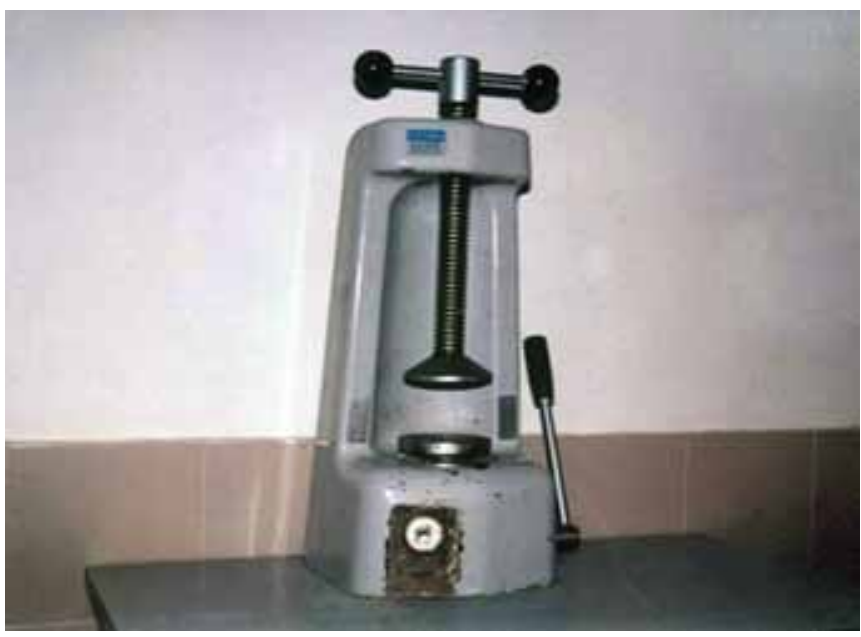

Fig. 12: Hydraulic press

by compression molding as per standardized techniques. The flasks were trial packed using wet cellophane as a separator and compressed in a hydraulic press (Fig. 12) for 1 hour. Denture bases were cured in an acrylizer (Fig. 13) according to manufacturer's instructions. After curing, the flasks were allowed to cool overnight. Careful deflasking was done and the denture bases were not separated from their respective casts (Fig. 14).

The distance of above-mentioned reference marks was measured on the processed denture bases using the same traveling microscope (Fig. 15). The reading, thus, obtained was compared with the previous readings. In this manner, the linear dimensional changes in each of the 90 denture bases were calculated.

The readings in cited areas on the processed denture bases were subtracted from the respective readings on temporary denture bases to calculate the dimensional changes after processing in respective directions. The positive sign denotes contraction or decrease in the 

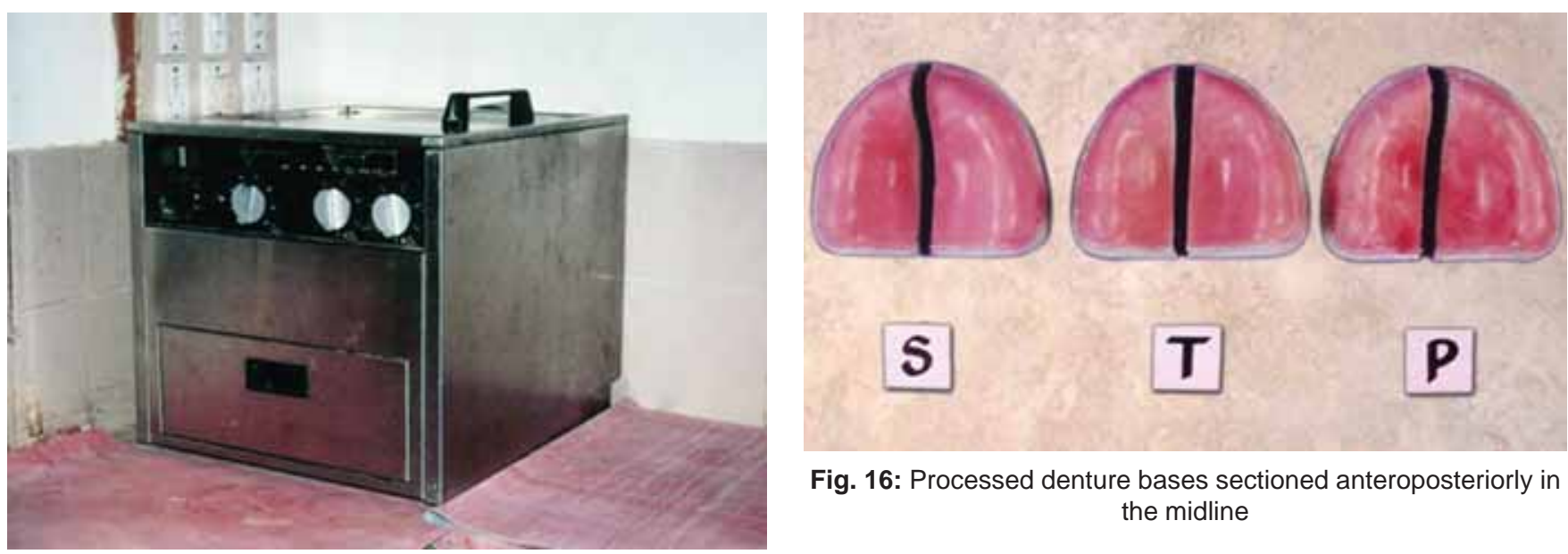

Fig. 16: Processed denture bases sectioned anteroposteriorly in the midline

Fig. 13: Acrylizer

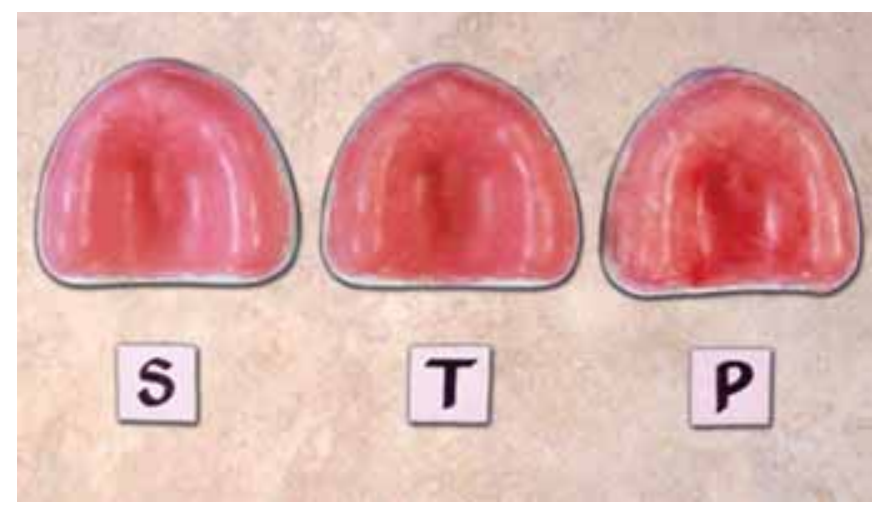

Fig. 14: Processed denture bases

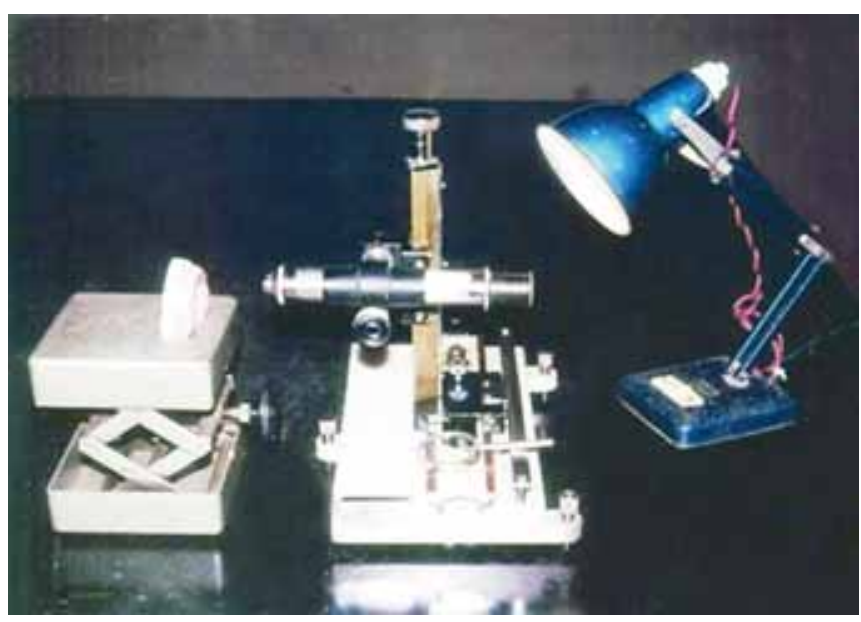

Fig. 15: Method used for measuring the distances between reference marks in processed denture bases

dimension, whereas the negative sign denotes expansion or increase in the dimensions in respective areas.

Last fifteen casts (S16-S30, T16-T30 and P16-P30) with the processed denture bases from each group were sectioned anteroposteriorly in the midline using a diamond disk (Fig. 16) three marks were placed on the sectioned portion (Figs 17 and 18).

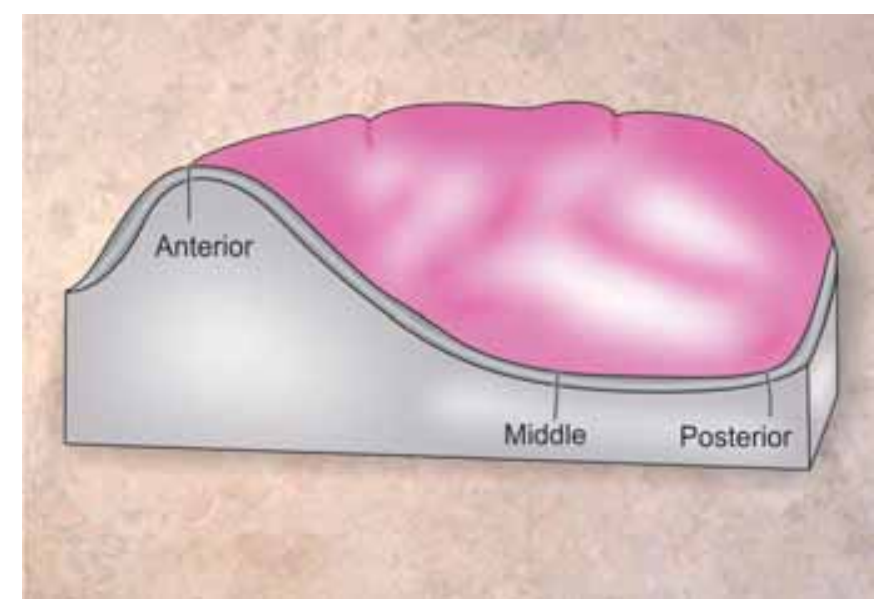

Fig. 17: Reference marks in anterior, middle and posterior regions after sectioning the samples anteroposteriorly in the midline

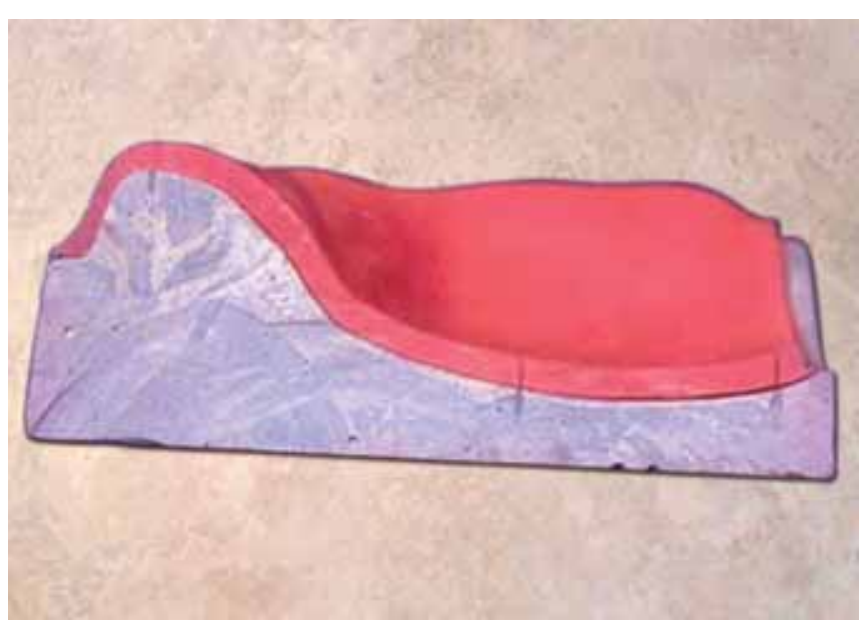

Fig. 18: Reference marks in the processed denture base in anterior, middle and posterior regions after sectioning anteroposteriorly in the midline

1. Anterior-Anterior maxillary ridge.

2. Middle-Mid-palatal area.

3. Posterior-Posterior termination of the base.

4. The amount of space between the tissue surface of the processed denture base and the cast in anterior, middle and posterior regions were measured using the same traveling microscope (Fig. 19). 
All the ninety denture bases were separated from their casts and were immersed in water for 17 days to evaluate the effect of water sorption (Fig. 20). To calculate the dimensional changes in processed denture bases after immersion in water for 17 days, the readings on processed denture bases after 17 days were subtracted from the respective readings on the processed denture bases obtained after processing.

These dimensional changes form the basic data for this study. Mean and standard deviation were calculated for these dimensional changes and were subjected to statistical analysis (Student's t-test, unpaired). The findings of the

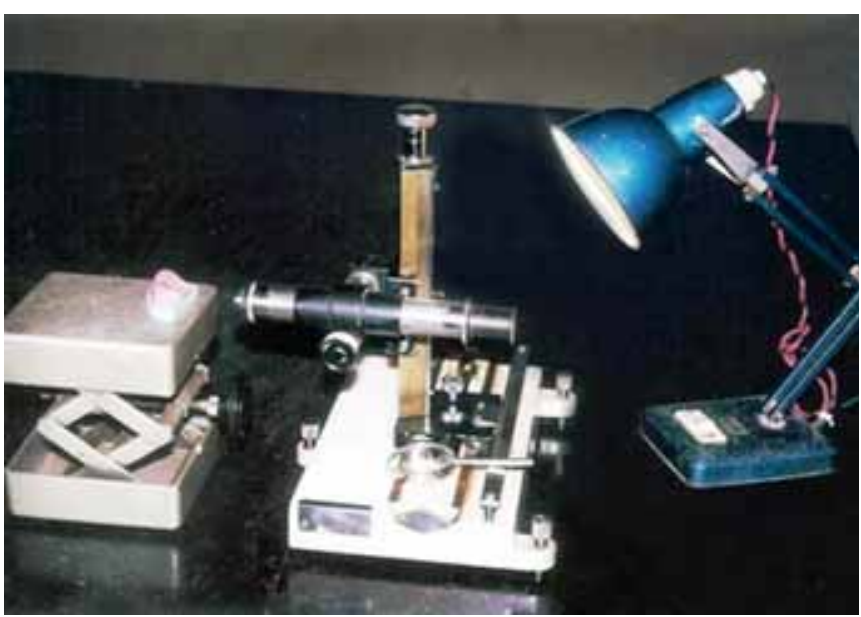

Fig. 19: Method used for measuring the amount of space between the processed denture base and the cast after sectioning anteroposteriorly in the midline

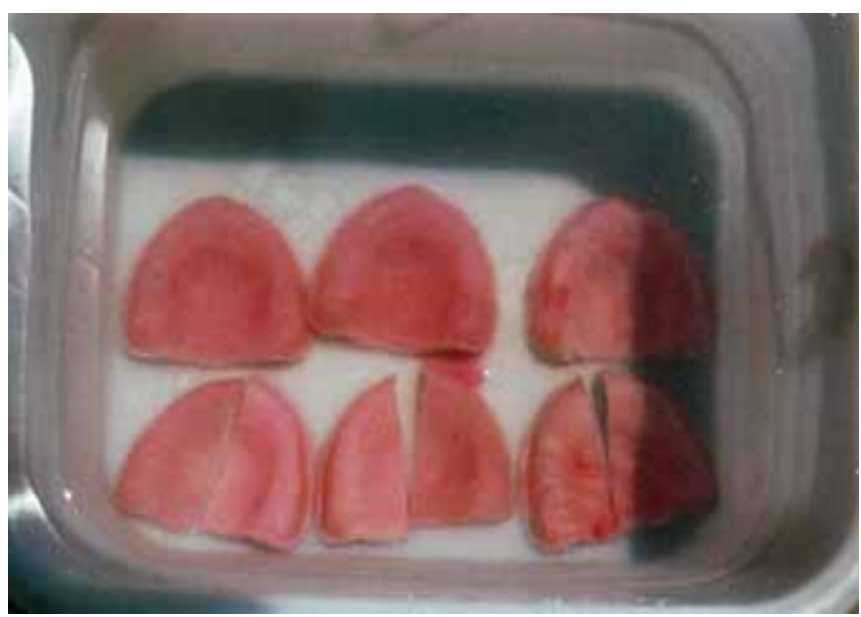

Fig. 20: Processed denture bases immersed in water study as well as statistical analysis have been presented in tabulated from in the chapter of results.

\section{RESULTS}

The dimensional changes in the denture bases after processing and after immersion in water for 17 days were calculated by measuring by the distance between the reference marks as shown in Figs 8 and 17 using a traveling microscope having a least count of $0.001 \mathrm{~cm}$ (Graphs 1 to 8).

Tables 1 and 2 show the mean and standard deviation of the dimensional changes from temporary denture bases to processed denture bases of thirty samples of each group, and the mean and standard deviation of the dimensional changes in processed denture bases of first fifteen samples from each group after immersion in water for 17 days respectively in the region of canine-to-canine (C-C), second molar-to-second molar (IIM-IIM), canine-to-second molar (C-IIM) on right and left sides for $\mathrm{S}, \mathrm{T}$ and $\mathrm{P}$ groups.

Tables 3 and 4 show the mean and standard deviation of the amount of space between the processed denture base and the cast, and the mean and standard deviation of the amount of space between the processed denture base and the cast in last 15 samples from each group after immersion in water for 17 days respectively in anterior, middle and posterior for $\mathrm{S}, \mathrm{T}$ and $\mathrm{P}$ groups.

The obtained mean values and standard deviation were subjected to Student's t-test, unpaired, statistical comparisons and their significance were calculated. The comparative values and their significance are presented in Tables 5 to 8.

The abbreviations used in the Tables:

Group S - Nonreinforced heat-cured poly (methyl methacrylate) resin.

Group T - High impact heat-cured poly (methyl methacrylate) resin.

Group P - Fiberglass reinforced heat-cured poly (methyl methacrylate) resin.

Among each group, it was numbered from 1 to 30

Example:

S1, S2, S3, S4 ..............

T1, T2, T3, T4

P1, P2, P3, P4

Table 1: Mean and standard deviation of the dimensional changes from temporary denture bases to processed denture bases in different regions of $\mathrm{S}, \mathrm{T}$ and $\mathrm{P}$ groups (Thirty samples of each group)

\begin{tabular}{|c|c|c|c|c|c|c|c|c|}
\hline \multirow[t]{3}{*}{ Groups } & \multicolumn{2}{|c|}{$C-C$} & \multicolumn{2}{|c|}{ IIM-IIM } & \multicolumn{4}{|c|}{$C-I I M$} \\
\hline & \multirow[b]{2}{*}{ Mean } & \multirow[b]{2}{*}{$S D$} & \multirow[b]{2}{*}{ Mean } & \multirow[b]{2}{*}{$S D$} & \multicolumn{2}{|c|}{ Right } & \multicolumn{2}{|c|}{ Left } \\
\hline & & & & & Mean & $S D$ & Mean & $\overline{S D}$ \\
\hline S & +0.032 & 0.017 & +0.031 & 0.016 & +0.037 & 0.020 & +0.039 & 0.017 \\
\hline $\mathrm{T}$ & +0.044 & 0.016 & +0.040 & 0.019 & +0.044 & 0.020 & +0.044 & 0.022 \\
\hline$P$ & +0.057 & 0.023 & +0.055 & 0.024 & +0.055 & 0.023 & +0.055 & 0.020 \\
\hline
\end{tabular}


The Effect of Fiber Reinforcement on the Dimensional Changes of Poly Methyl Methacrylate Resin

\begin{tabular}{llllllll}
\hline \multicolumn{3}{c}{ Table 2: Mean and standard deviation of the dimensional changes in processed denture bases after immersion in water for } \\
17 days in different regions of S, T and P groups (First fifteen samples of each group)
\end{tabular}

\begin{tabular}{|c|c|c|c|c|c|c|}
\hline \multirow[t]{2}{*}{ Groups } & \multicolumn{2}{|c|}{ Anterior } & \multicolumn{2}{|c|}{ Middle } & \multicolumn{2}{|c|}{ Posterior } \\
\hline & Mean & $S D$ & Mean & $S D$ & Mean & $S D$ \\
\hline $\mathrm{S}$ & 0.017 & 0.006 & 0.022 & 0.010 & 0.035 & 0.011 \\
\hline $\mathrm{T}$ & 0.019 & 0.009 & 0.027 & 0.009 & 0.037 & 0.009 \\
\hline$P$ & 0.023 & 0.009 & 0.029 & 0.009 & 0.038 & 0.010 \\
\hline
\end{tabular}

Table 4: Mean and standard deviation of the amount of space between the processed denture bases and the cast after immersion in water for 17 days in different regions of $\mathrm{S}, \mathrm{T}$ and $\mathrm{P}$ groups (Last fifteen samples of each group)

\begin{tabular}{|c|c|c|c|c|c|c|}
\hline \multirow[t]{2}{*}{ Groups } & \multicolumn{2}{|c|}{ Anterior } & \multicolumn{2}{|c|}{ Middle } & \multicolumn{2}{|c|}{ Posterior } \\
\hline & Mean & $S D$ & Mean & $S D$ & Mean & $S D$ \\
\hline S & 0.006 & 0.005 & 0.012 & 0.007 & 0.018 & 0.011 \\
\hline $\mathrm{T}$ & 0.009 & 0.007 & 0.016 & 0.011 & 0.021 & 0.012 \\
\hline$P$ & 0.010 & 0.006 & 0.016 & 0.011 & 0.024 & 0.012 \\
\hline
\end{tabular}

Table 5A: Statistical comparison (Student t-test, unpaired) of dimensional changes from temporary denture bases to processed denture bases between different groups in $\mathrm{C}-\mathrm{C}$ region

\begin{tabular}{lcclc}
\hline Groups & $\begin{array}{c}\text { No. of } \\
\text { samples }\end{array}$ & t-value & $p$-value & Significance \\
\hline $\mathrm{S}$ and T & 60 & 2.7714 & $<0.01$ & $\mathrm{~S}$ \\
$\mathrm{~S}$ and P & 60 & 4.7072 & $<0.001$ & $\mathrm{HS}$ \\
T and P & 60 & 2.4987 & $<0.05$ & $\mathrm{~S}$ \\
\hline
\end{tabular}

S: Significant; HS: Highly significant

Table 5B: Statistical comparison (Student t-test, unpaired) of dimensional changes from temporary denture bases to processed denture bases between different groups in IIM-IIM region

\begin{tabular}{lcclc} 
Groups & $\begin{array}{l}\text { No. of } \\
\text { samples }\end{array}$ & $t$-value & $p$-value & Significance \\
\hline S and T & 60 & 1.09512 & $<0.05$ & $\mathrm{NS}$ \\
S and P & 60 & 4.04807 & $<0.001$ & $\mathrm{HS}$ \\
T and P & 60 & 2.6389 & $<0.05$ & $\mathrm{~S}$ \\
\hline
\end{tabular}

NS: Nonsignificant; S: Significant; HS: Highly significant

$\mathrm{C}-\mathrm{C}$

- Canine-to-canine

IIM-IIM - Second molar-to-second molar

C-IIM (Right) - Canine-to-second molar on the right side

C-IIM (Left) - Canine-to-second molar on the side

'+' ve sign - Denotes contraction or decrease in the dimensions
Tables 5C and D: Statistical comparison (Student t-test, unpaired) of dimensional changes from temporary denture bases to processed denture bases between different groups in C-IIM region on the left side

\begin{tabular}{lcclc}
\hline C & & & & \\
\hline Groups & $\begin{array}{c}\text { No. of } \\
\text { samples }\end{array}$ & $t$-value & $p$-value & Significance \\
\hline S and T & 60 & 0.1356 & $<0.05$ & NS \\
S and P & 60 & 3.1803 & $<0.001$ & NS \\
T and P & 60 & 1.9435 & $<0.05$ & NS \\
\hline D & & & & \\
\hline Groups & No. of & $t$-value & $p$-value & Significance \\
& samples & & & \\
\hline S and T & 60 & 0.8654 & $>0.05$ & NS \\
S and P & 60 & 4.2572 & $<0.001$ & HS \\
T and P & 60 & 1.9925 & $>0.05$ & NS \\
\hline
\end{tabular}

NS: Nonsignificant; HS: Highly significant

Tables 6A and B: Statistical comparison (Students t-test, unpaired) of dimensional changes in processed bases after immersion in water for 17 days bases between different groups in $\mathrm{C}-\mathrm{C}$ region

\begin{tabular}{lcclc}
\hline A & & & & \\
\hline Groups & $\begin{array}{c}\text { No. of } \\
\text { samples }\end{array}$ & t-value & $p$-value & Significance \\
\hline S and T & 30 & 1.9506 & $>0.05$ & NS \\
S and P & 30 & 2.6966 & $<0.001$ & $\mathrm{~S}$ \\
T and P & 30 & 0.5719 & $>0.05$ & NS \\
\hline B & & & & \\
\hline Groups & No. of & t-value & $p$-value & Significance \\
& samples & & & \\
\hline S and T & 30 & 1.4298 & $>0.05$ & NS \\
S and P & 30 & 2.0597 & $<0.001$ & $\mathrm{~S}$ \\
T and P & 30 & 1.0000 & $>0.05$ & $\mathrm{NS}$ \\
\hline
\end{tabular}

NS: Nonsignificant; S: Significant

‘-' ve sign - Denotes expansion or increase in the dimensions

NS $\quad-$ Nonsignificant

S $\quad-$ Significant

HS - Highly significant.

\section{DISCUSSION}

The dimensional accuracy of denture bases should be as high as possible since the closeness of the denture base and 
Table 6C: Statistical comparison (Students 't' test, unpaired) of dimensional changes in processed bases after immersion in water for 17 days bases between different groups in C-IIM region on the right side

\begin{tabular}{lcccc}
\hline Groups & $\begin{array}{l}\text { No. of } \\
\text { samples }\end{array}$ & t-value & $p$-value & Significance \\
\hline S and T & 30 & 1.2091 & $>0.05$ & NS \\
S and P & 30 & 1.6620 & $>0.05$ & NS \\
T and P & 30 & 0.5412 & $>0.05$ & NS
\end{tabular}

NS: Nonsignificant

\begin{tabular}{|c|c|c|c|c|}
\hline Groups & $\begin{array}{l}\text { No. of } \\
\text { samples }\end{array}$ & $t$-value & $p$-value & Significance \\
\hline $\mathrm{S}$ and $\mathrm{T}$ & 30 & 0.5563 & $>0.05$ & NS \\
\hline $\mathrm{S}$ and $\mathrm{P}$ & 30 & 1.2474 & $>0.05$ & NS \\
\hline $\mathrm{T}$ and $\mathrm{P}$ & 30 & 0.7187 & $>0.05$ & NS \\
\hline
\end{tabular}

NS: Nonsignificant

Table 7A: Statistical comparison (Student t-test, unpaired) of the amount of space between the processed denture bases and the cast between different groups in the anterior region

\begin{tabular}{lcccc}
\hline Groups & $\begin{array}{l}\text { No. of } \\
\text { samples }\end{array}$ & t-value & $p$-value & Significance \\
\hline S and T & 30 & 0.6912 & $>0.05$ & NS \\
S and P & 30 & 2.0758 & $>0.05$ & S \\
T and P & 30 & 1.2173 & $>0.05$ & NS \\
\hline
\end{tabular}

NS: Nonsignificant; S: Significant

Table 7B: Statistical comparison (Students t-test, unpaired) of the amount of space between the processed denture bases and the cast between different groups in the middle region

\begin{tabular}{lcccc}
\hline Groups & $\begin{array}{c}\text { No. of } \\
\text { samples }\end{array}$ & t-value & $p$-value & Significance \\
\hline S and T & 30 & 1.3908 & $>0.05$ & NS \\
S and P & 30 & 1.9471 & $>0.05$ & NS \\
T and P & 30 & 0.6087 & $>0.05$ & NS \\
\hline
\end{tabular}

NS: Nonsignificant

Table 7C: Statistical comparison (Students t-test, unpaired) of the amount of space between the processed denture bases and the cast between different groups in the posterior region

\begin{tabular}{lcccc}
\hline Groups & $\begin{array}{c}\text { No. of } \\
\text { samples }\end{array}$ & t-value & $p$-value & Significance \\
\hline S and T & 30 & 0.5266 & $>0.05$ & NS \\
S and P & 30 & 0.6898 & $>0.05$ & NS \\
T and P & 30 & 0.2781 & $>0.05$ & NS \\
\hline
\end{tabular}

NS: Nonsignificant

the tissues is one of the principal factors in retention. Fortunately, the oral tissues have remarkable ability of adapting their contours to those of the dentures. This has been shown in studies of the tissue changes which occurred under the denture bases. However, the fact that the tissue
Table 8A: Statistical comparison (Student t-test, unpaired) of the amount of space between the processed denture bases and the cast after immersion in the water for 17 days between different groups in the anterior region

\begin{tabular}{lcccc}
\hline Groups & $\begin{array}{l}\text { No. of } \\
\text { samples }\end{array}$ & t-value & $p$-value & Significance \\
\hline S and T & 30 & 1.3051 & $>0.05$ & NS \\
S and P & 30 & 1.9165 & $>0.05$ & NS \\
T and P & 30 & 0.4059 & $>0.05$ & NS \\
\hline
\end{tabular}

NS: Nonsignificant

Table 8B: Statistical comparison (Students t-test, unpaired) of the amount of space between the processed denture bases and the cast after immersion in the water for 17 days between different groups in the middle region

\begin{tabular}{lcccc}
\hline Groups & $\begin{array}{c}\text { No. of } \\
\text { samples }\end{array}$ & t-value & $p$-value & Significance \\
\hline S and T & 30 & 1.1480 & $>0.05$ & NS \\
S and P & 30 & 1.1480 & $>0.05$ & NS \\
T and P & 30 & 0.0000 & $>0.05$ & NS \\
\hline
\end{tabular}

NS: Nonsignificant

Table 8C: Statistical comparison (Student t-test, unpaired) of the amount of space between the processed denture bases and the cast after immersion in the water for 17 days between different groups in the posterior region

\begin{tabular}{lcccc}
\hline Groups & $\begin{array}{l}\text { No. of } \\
\text { samples }\end{array}$ & t-value & $p$-value & Significance \\
\hline S and T & 30 & 0.6896 & $>0.05$ & NS \\
S and P & 30 & 1.3793 & $>0.05$ & NS \\
T and P & 30 & 0.6847 & $>0.05$ & NS \\
\hline
\end{tabular}

NS: Nonsignificant

change does not signify that they are healthy when they do change or that they remain stable over a period of time under those conditions. In order to maintain healthy and stable oral tissues, every effort should be made to provide dentures which fit accurately and which will minimize the amount of tissue change. ${ }^{4}$

However, due to the polymerization shrinkage, intimacy of contact of the denture base with the tissues is lost. The presence of space between the denture base and the supporting tissues affect denture retention and stability as well as cause discrepancies in planned and established occlusion. ${ }^{4}$ Moreover, water sorption property of the polymer also leads to dimensional changes in the denture bases. ${ }^{9}$ These dimensional changes may also be affected by incorporation of fillers for reinforcement to improve certain properties of heat-cured poly (methyl methacrylate) resin.

Various investigators have used a variety of methods to determine the dimensional changes occurring in heat-cured poly (methyl methacrylate) resin after processing and after immersion in water.

Peyton FA and Anthony $\mathrm{DH}^{4}$ quoted that the dimensional changes were assessed by Tuck filed WJ, Warner HK and Guerin BC by placing the dentures lightly 


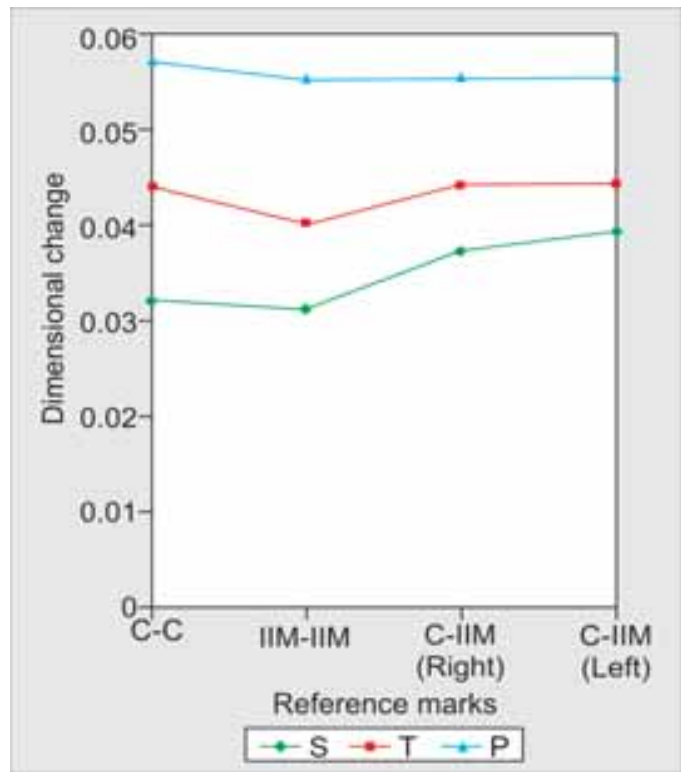

Graph 1: Graphical representation (Line diagram) of the dimensional changes from temporary denture bases to processed denture bases (Thirty samples of each group)

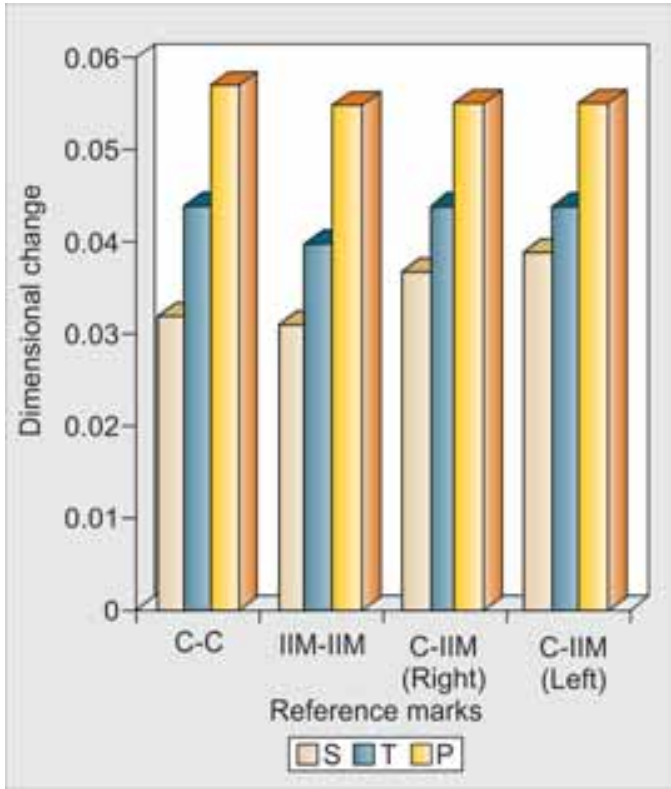

Graph 2: Graphical representation (Bar diagram) of the dimensional changes from temporary denture bases to processed denture bases (Thirty samples of each group)

on the master cast and observing the discrepancies at the denture border and by Skinner EW and Cooper EN by measuring the discrepancies at the posterior border, while the dentures were held in position.

Woelfel JB, Paffenbarger GC and Sweeney $\mathrm{WT}^{21}$ studied dimensional changes in dentures by placing metal pins in the molar tooth region of the dentures and then measuring any changes with aid of micrometer microscope. In this study, the dimensional changes are measured by using cusp tips of the teeth as reference points, and the space

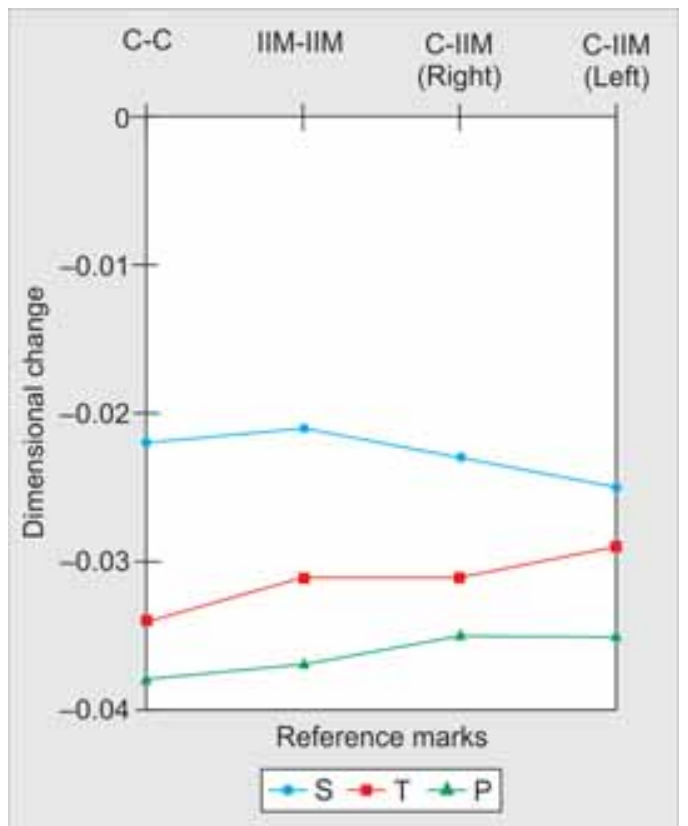

Graph 3: Graphical representation (Line diagram) of dimensional changes in processed denture bases in first fifteen samples from each group after immersion in water for 17 days

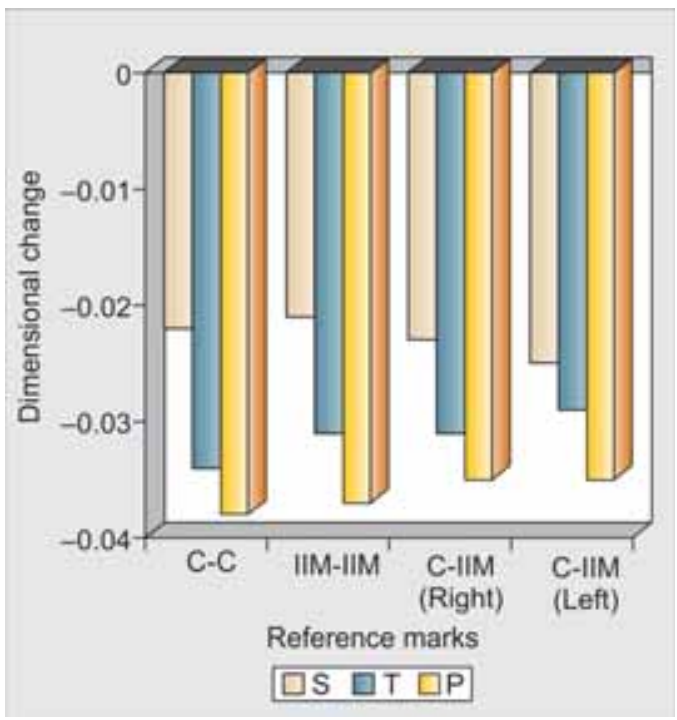

Graph 4: Graphical representation (Bar diagram) of the dimensional changes in processed denture bases in first fifteen samples from each group after immersion in water for 17 days

between the denture bases was measured after sectioning them.

Becker CM, Smith DE and Nicholls $\mathrm{JI}^{8}$ stated that the crest of the ridge is the logical reference plane from a clinical point of view, since this is the primary stress-bearing of the maxillary denture, as has also been discussed by Pendelton EC et al.

Ryge $\mathrm{G}$ and Fairhurst $\mathrm{CW}^{22}$ stated that the dimensional changes responsible for the difference in adaptation of the denture at different stages, occur in three-dimensions in 


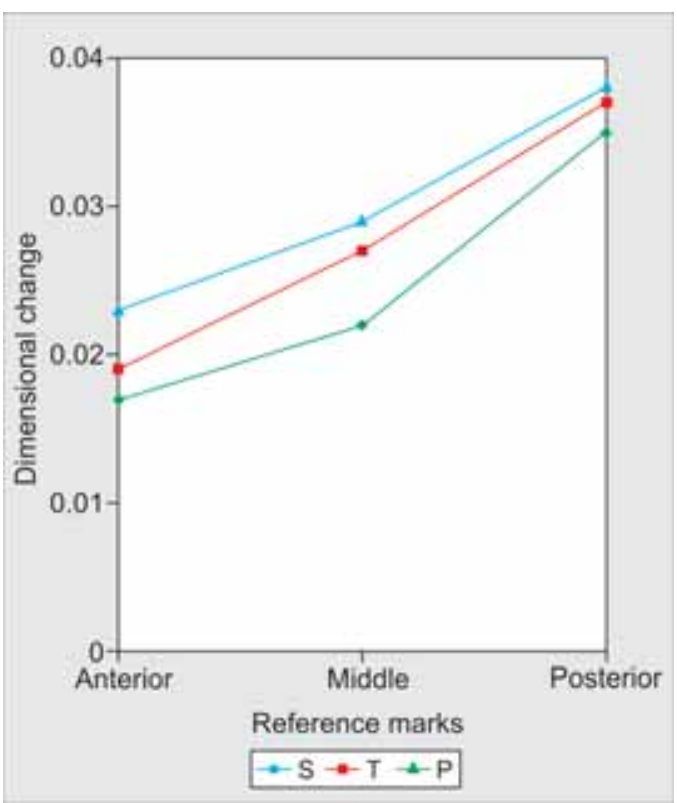

Graph 5: Graphical representation (Line diagram) of the amount of space between the processed denture base and the case in last fifteen samples form each group

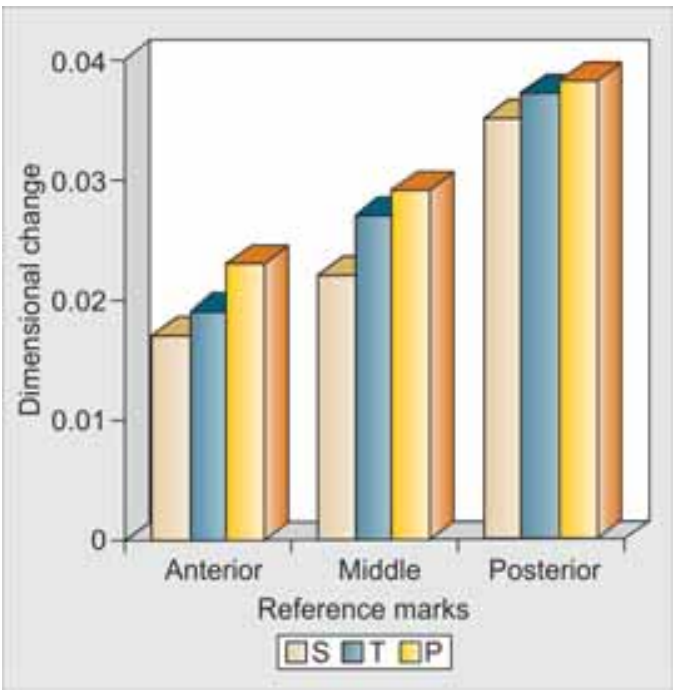

Graph 6: Graphical representation (Bar diagram) of the amount of space between the processed denture base and the cast in last fifteen samples form each group

several planes. Hence, they disagreed with the views and findings of the earlier workers who had determined the linear dimensional changes as an indication of the fit of the dentures.

Patil NP and Hegde $\mathrm{VK}^{23}$ quoted that Skinner EW and Jones PM found that the shrinkage due to curing was not confined to one region alone, instead it would be distributed over all the surface of the dentures.

Based on the above facts, the present study was carried out to evaluate the effect of fiber reinforcement on the

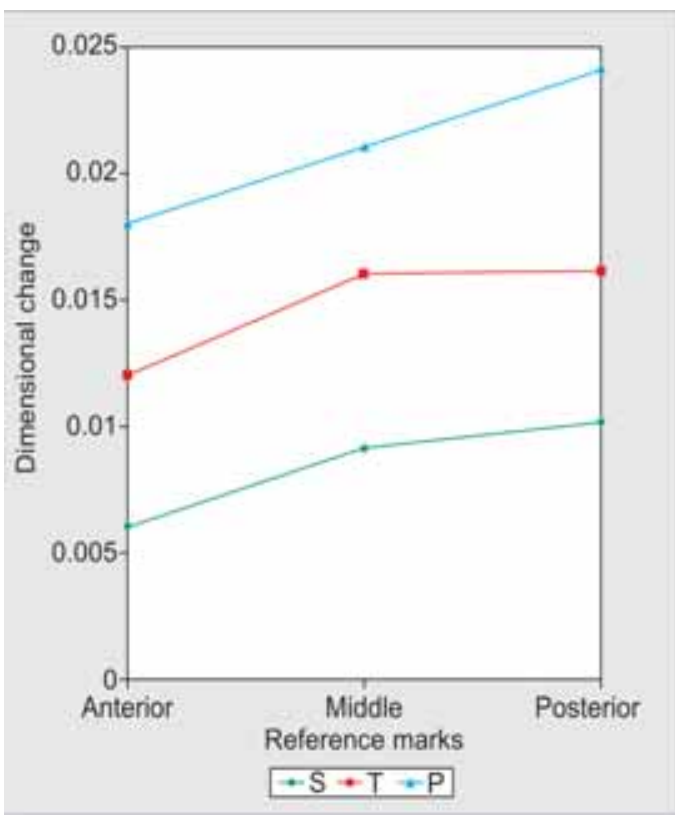

Graph 7: Graphical representation (Line diagram) of the amount of space between the processed denture base and the cast in last fifteen samples from each group after immersion in water for 17 days

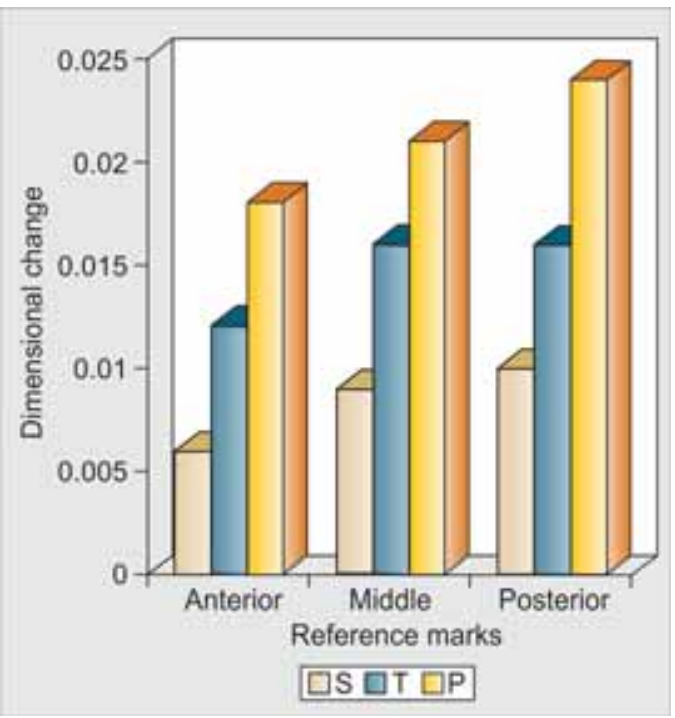

Graph 8: Graphical representation (Bar diagram) of the amount of space between the processed denture base and the cast in last fifteen samples form each group after immersion in water for 17 days

dimensional changes of heat-cured poly (methyl methacrylate) resin and to compare the dimensional changes occurring in three type of heat-cured poly methacrylate resin is, i.e. nonreinforced heat-cured poly (methyl methacrylate) resin, high impact heat-cure poly (methyl methacrylate) resin and fiberglass reinforced heat-cured poly (methyl methacrylate) resins in different planes and in different regions after processing and after immersion on water. These three planes are in the direction of side-to-side in canine and molar region, anteroposterior, i.e. canine-to-molar 
region and vertical, i.e. between tissue surface of the processed denture bases and the cast after sectioning them in the midline.

The absence of denture teeth in the samples eliminated the variable of tooth movement during investing and processing. The resulting dimensional changes were directly attributable to the polymerization of the resin and to the relatively negligible dimensional changes of the investing material.

The dimensional changes due to processing in the region of canine-to-canine, second molar-to-second molar and canine-to-second molar on right and it is evident that the mean dimensional change after processing in the region of canine-to-canine, second molar-to-second molar and canineto-second molar on right and left sides is in the following decreasing order - group ' $\mathrm{P}$ ', group ' $\mathrm{T}$ ' and group ' $\mathrm{S}$ '.

As per the above results, it is evident that group 'P', i.e. fiberglass reinforced heat-cured poly (methyl methacrylate) resin showed lowest dimensional accuracy after processing when compared with ' $\mathrm{S}$ ' and ' $\mathrm{T}$ ' groups, i.e. nonreinforced and high impact heat-cured poly (methyl methacrylate) resins respectively in all the three planes. This may be due to the high polymerization shrinkage of methyl methacrylate in the fiberglass reinforced samples.

These findings are in agreement with the study of Vallittu $\mathrm{PK}^{24}$ who showed that the lowest dimensional accuracy was found in fiberglass reinforced specimens made from heatcured poly (methyl methacrylate) and suggested that this was caused by the polymerization shrinkage of the methyl methacrylate in the reinforcement.

The amount of space between the processed denture base and the cast after it was sectioned anteroposteriorly in the midline with the study of Anthonv DH and Pevton $\mathrm{FA}^{4}$ who stated that the processing shrinkage with the premature contacts of the denture base with the cast in these regions cause the denture base to be pulled away or raised from the cast in the palatal region.

Poly (methyl methacrylate) absorbs water and expand slowly over a period of time. Miettinen VM and Vallittu $\mathrm{PK}^{25}$ stated that this expansion is a volumetric change and can be attributed to the polar properties of the resin molecules. Braden $\mathrm{M}^{9}$ showed that the water molecules act according to the laws of diffusion and that the kinetics of water absorption obeyed the mathematical laws of diffusion.

The diffusion presumably occurs between the molecules mobile, and the inherent stresses created during heat-curing of the acrylic resin can be relieved with consequent intermolecular relaxation and possible change in the shape of the denture.

Immersion time also plays a significant role in water sorption. Anusavice $\mathrm{KJ}^{6}$ found that a typical acrylic resin denture may take a period of almost 17 days to become fully saturated with water.

It is evident that the mean dimensional change after processing in the region of canine-to-canine, second molarto-second molar and canine-to-second molar on right and left sides is in the following decreasing - group ' $\mathrm{P}$ ', group ' $T$ ' and group ' $S$ '.

As per the above results, it is evident that group 'P', i.e. fiberglass reinforced heat-cured poly (methyl methacrylate) resin showed lowest dimensional accuracy after processing when compared with ' $\mathrm{S}$ ' and ' $\mathrm{T}$ ' groups, i.e. nonreinforced and high impact heat-cured poly (methyl methacrylate) resins respectively in all the three planes. This may be due to the high polymerization shrinkage of methyl methacrylate in the fiberglass reinforced samples.

These findings are in agreement with study of Vallittu $\mathrm{PK}^{24}$ who showed that the lowest dimensional accuracy was found in fiberglass reinforced specimens made from heatcured poly (methyl methacrylate) and suggested that this was caused by the polymerization shrinkage of the methyl methacrylate in the reinforcement.

The amount of space between the processed denture base and the cast after it was sectioned anteroposteriorly in the midline were consistent with the study of Anthony DH and Peyton $\mathrm{FA}^{4}$ who stated that the processing shrinkage which occurred in the maxillary denture tended to draw the flanges inward. As a result, in the second phase of the present study, all the processed denture bases were immersed in water for 17 days to determine the effect of water sorption. Upon statistical analysis by using Student's t-test, unpaired, the dimensional changes after processing in three types of heatcured poly (methyl methacrylate) resins in different regions were compared with each other (Tables 1 to 4 ).

In the region of canine-to-canine, when group ' $S$ ' was compared with group ' $\mathrm{T}$ ' and group ' $\mathrm{T}$ ' with group ' $\mathrm{P}$, it was found to be statistically significant at $1 \%$ and $5 \%$ level of significance respectively (t-value 2.7714 and 2.4987 respectively). When group ' $\mathrm{S}$ ' was compared with group ' $\mathrm{P}$ ', it was found to be statistically highly significant at $0.1 \%$ level of significance (t-value 4.7072).

In the region of second molar-to-second molar, when group ' $S$ ' was compared with group ' $T$ ', it was found to be statistically nonsignificant at $5 \%$ level of significance (tvalue 1.9512). when group ' $T$ ' was compared with group 'P', it was found to be statistically significant at $5 \%$ level of significance ( $t$-value 2.6389). When group ' $S$ ' was compared with group 'P', it was found to be statistically highly significant at 0.1 present level of significance ( $t$-value 4.4807).

In the region of canine-to-second molar on the right side, when group ' $\mathrm{S}$ ' was compared with group ' $\mathrm{T}$ ', and group 
'T' with group 'P', it was found to be statistically nonsignificant at 5\% level of significance (t-value 0.1356 and 1.9435 respectively). When group ' $\mathrm{S}$ ' was compared with group ' $\mathrm{P}$ ', it was found to be statistically significant at $1 \%$ level of significance (t-value 3.1803).

In the region of canine-to-second molar on the left side, who group ' $S$ ' was compared with group ' $T$ ' and group ' $T$ ' with group ' $\mathrm{P}$ ', it was found to be statistically nonsignificant at $5 \%$ level of significance (t-value 0.8654 and 1.9925 respectively). When group ' $\mathrm{S}$ ' was compared with group 'P', it was found to be statistically highly significant at $0.1 \%$ level of significance (t-value 4.2572).

After sectioning the processed denture bases with the casts in the midline (last fifteen samples from each group), the amount of space between the processed denture base and the cast in anterior, middle and posterior regions in three types of heat-cured poly (methyl methacrylate) resins were statistically compared with each other (Tables 5 to 8).

In the anterior region, when group ' $S$ ' was compared with group ' $\mathrm{T}$ ' and group ' $\mathrm{T}$ ' with group ' $\mathrm{P}$ ', it was found to be statistically nonsignificant at $5 \%$ level of significance (t-value 0.6912 and 1.2173 respectively). When group ' $\mathrm{S}$ ' was compared with group 'P', it was found to be statistically significant at $5 \%$ level of significance (t-value 2.0758).

In the middle region, when group ' $S$ ' was compared with group ' $\mathrm{T}$ ', group ' $\mathrm{T}$ ' with group ' $\mathrm{P}$ ' and ' $\mathrm{S}$ ' with group ' $\mathrm{P}$ ', it was found to be statistically nonsignificant at $5 \%$ level of significance (t-value 1.3908, 0.6087 and 1.9471 respectively).

In the posterior region, when group ' $\mathrm{S}$ ' was compared with group ' $\mathrm{T}$ ', group ' $\mathrm{T}$ ' with group ' $\mathrm{P}$ ' and group ' $\mathrm{S}$ ' with group ' $\mathrm{P}$ ', it was found to be statistically nonsignificant at $5 \%$ level of significance (t-value $0.5266,0.2781$ and 0.6898 respectively).

In the second phase of the study, the processed denture bases (first 15 samples from each group) were immersed in water for 17 days, and then statistically analyzed.

In the region of canine-to-canine, when group ' $\mathrm{S}$ ' was compared with group ' $\mathrm{T}$ ' and group ' $\mathrm{T}$ ' with group ' $\mathrm{P}$ ', it was found to be statistically nonsignificant at 5\% level of significance (t-value 1.9506 and 0.5719 respectively). When group ' $\mathrm{S}$ ' was compared with group ' $\mathrm{P}$ ', it was found to be statistically significant at $5 \%$ level of significance (t-value 2.6966).

In the region of second molar-to-second molar, when group ' $\mathrm{S}$ ' was compared with group ' $\mathrm{T}$ ' and group ' $\mathrm{P}$ ', it was found to statistically nonsignificant at 5\% level of significance (t-value 1.4298 and 1.0000 respectively). When group ' $\mathrm{S}$ ' was compared with group ' $\mathrm{P}$ ', it was found to be statistically significant at $5 \%$ level of significance (t-value 2.0597).
In the region of canine-to-second molar on the right side, when group ' $S$ ' was compared with group ' $T$ ', group ' $T$ ' with group ' $\mathrm{P}$ ' and group ' $\mathrm{S}$ ' with group ' $\mathrm{P}$ ', it was found to be statistically nonsignificant at $5 \%$ level of significance (t-value $1.2091,0.5412$ and 1.6620 respectively).

In the region of canine-to-second molar on the left side, when group ' $\mathrm{S}$ ' was compared with group ' $\mathrm{T}$ ', group ' $\mathrm{P}$ ' and group ' $\mathrm{S}$ ' with group ' $\mathrm{P}$ ', it was found to be statistically nonsignificant at $5 \%$ level of significance (t-value 0.5563 , 0.7187 and 1.2474 respectively).

The amount of space between the sectioned processed denture base and the cast (last fifteen samples from each group) in three types of heat-cured poly (methyl methacrylate) resins after immersion in water for 17 days were statistically compared with each other. In the anterior region, when group ' $S$ ' was compared with group ' $T$ ', group ' $T$ ' with group ' $\mathrm{P}$ ' and group ' $\mathrm{S}$ ' with group ' $\mathrm{P}$ ', it was found to be statistically nonsignificant at 5\% level of significance (t-value 1.3051, 0.4059 and 1.9165 respectively).

In the middle region, when group ' $S$ ' was compared with group ' $\mathrm{T}$ ', group ' $\mathrm{T}$ ' with group ' $\mathrm{P}$ ' and group ' $\mathrm{S}$ ' with group ' $\mathrm{P}$ ', it was found to be statistically nonsignificant at $5 \%$ level of significance (t-value 1.1480, 0 and 1.1480 respectively).

In the posterior region, when group ' $\mathrm{S}$ ' was compared with group ' $\mathrm{T}$ ', group ' $\mathrm{T}$ ' with group ' $\mathrm{P}$ ' and group ' $\mathrm{S}$ ' with group ' $\mathrm{P}$ ', it was found to be statistically nonsignificant at $5 \%$ level of significance (t-value $0.6896,0.6847$ and 1.3793 respectively).

Though there were statistically significant differences between the three types of heat-cured poly (methyl methacrylate) resins studied, the magnitude of dimensional changes in the three groups is less than $1 \%$ which seems to have little clinical significance.

It is suggested that further clinical studies need to be carried out on the effect of reinforcing materials and cross linking agents on the dimensional changes due to processing and the effect of water sorption.

The result and conclusions are pertaining to the materials, method of preparation of samples and evaluation employed in this study. The magnitude of dimensional changes may differ if there are variations in any of the abovementioned procedures.

\section{CONCLUSION}

1. Dimensional changes were evident in all the planes in the three groups studied.

2. The denture bases of all the three groups showed contraction in the intercanine, intermolar and canine to molar distances on right and left sides after processing. 
3. The dimensional changes observed in the three groups after processing are in the following decreasing order fiberglass reinforced heat-cured poly (methyl methacrylate) resin, high impact heat-cured poly (methyl methacrylate) resin and nonreinforced heat-cured poly (methyl methacrylate) resin.

4. The amount of space observed between the tissue surface of the processed denture base and the cast are in the following decreasing order - fiberglass reinforced heatcured poly (methyl methacrylate) resin, high impact heatcured poly (methyl methacrylate) resin and nonreinforced heat-cured poly (methyl methacrylate) resin.

5. The denture bases of all the three groups showed expansion in the intercanine, intermolar and canine to molar distances on right and left sides after immersion in water for 17 days. This compensated in part for the shrinkage which occurred due to processing.

6. Fiberglass reinforcement can be used clinically since the magnitude of dimensional changes is less than $1 \%$ which seems to have little clinical significance.

\section{REFERENCES}

1. Al-Mulla MAS, Murphy WM, Huggett R, Brooks SC. Effect of water and artificial saliva on mechanical properties of some denture-base materials. Dent Mater 1989;5:399-402.

2. Anderson GC, Schulte JK, Arnold TG. Dimensional stability of injection and conventional processing of denture base acrylic resin. J Prosthet Dent 1988;60(3):394-98.

3. Anthony DH, Peyton FA. Evaluating dimensional accuracy of denture bases with a modified comparator. J Prosthet Dent 1959;9(4):683-92.

4. Anthony DH, Peyton FA. Dimensional accuracy of various denture base materials. J Prosthet Dent 1962;12(1):67-81.

5. Antonopoulos AN. Dimensional and occlusal changes in fluid resin dentures. J Prosthet Dent 1978;39(6):605-15.

6. Anusavice KJ. Phillips' science of dental materials (10th ed), WB Saunders Company, USA 1996;237-72.

7. Baemmert RJ, Langb R, Barco Jr MT, Billye J. The effects of denture teeth on the dimensional accuracy of acrylic resin denture bases. Int J Prosthodont 1990;3:528-37.

8. Becker CM, Smith DE, Nicholls JI. The comparison of denturebase processing techniques. Part II. Dimensional change due to processing. J Prosthet Dent 1977;37(4):450-59.

9. Braden M. The absorption of water by acrylic resins and other materials. J Prosthet Dent 1964;14(2):307-16.

10. Chen JC, Lacefiejd WR, Castleberry DJ. Effect of denture thickness and curing cycle on the dimensional stability of acrylic resin denture bases. Dent Mater 1988;4:20-24.

11. Chevitarese O, Craig RG, Peyton FA. Properties of various types of denture-base plastics. J Prosthet Dent 1962;12(4):711-18.

12. Craig RG, O’Brien WJ, Powers JM. Dental-materials properties and manipulation (4th ed), CV Mosby Co, St Louis, USA 1990;272-296.

13. Dabreo EL, Herman P. A new method of measuring dimensional change. J Prosthet Dent 1991;65(5):718-22.

14. Degee AJ, Tenharkel EC, Davidson CL. Measuring procedure for the determination of the three-dimensional shape of dentures. J Prosthet Dent 1979;42(2):149-53.
15. Dixon DL, Breeding LC, Ekstrand KG. Linear dimensional variability of three denture base resins after processing and in water storage, J Prosthet Dent 1992;68(1):196- 200.

16. Firtell DN, Green AJ, Elath JM. Posterior peripheral seal distortional related to processing temperature. J Prosthet Dent 1981;45(6):598-601.

17. Frejlich S, Dirckxj JJ, Goodacre CJ, Swartz ML, Andres CJ. Moire topography for measuring the dimensional accuracy of resin complete denture bases. Int J Prosthodont 1989;2:272-79.

18. Garfunkel E. Evaluation of dimensional change in complete denture processed by injection-pressing and the pack- and-press technique. J Prosthet Dent 1983;50(6):757-61.

19. Glazier S, Firtell DN, Harman LL. Posterior peripheral seal distortion related to height of the maxillary-ridge. J Prosthet Dent 1980;43(5):508-10.

20. Grant AA, Atkinson HF. Comparison between dimensional accuracy of denture produced with pour-type resin and with heat processed materials. J Prosthet Dent 1971;26(3):296-301.

21. Hardy F, Comparison of fluid resin and compression molding methods in processing dimensional change. J Prosthet Dent 1978;39(4):375-77.

22. Harvey WL, Harvey EV. Dimensional change at the posterior border of baseplates made from a visible light-activated composite resin. J Prosthet Dent 1989;62(2):184-89.

23. Huggett R, Bates JF, Knott NJ. Comparison of some properties of denture base acrylic resins polymerized by dry and wet curing systems. Quint Dent Tech 1996;11(4):265-69.

24. Huggeti R, Zissis A, Harrison A, Dennis A. Dimensional accuracy and stability of acrylic resin denture bases. J Prosthet Dent 1999;68(4):634-40.

25. Jackson AD, Grisins RJ, Fenster RK, Lang BR. The dimensional accuracy of two denture base processing methods. Int $\mathrm{J}$ Prosthodont 2008;2:421-28.

26. Joshnston EP, Nicholls JI, Smith DE. Flexure fatigue of 10 commonly used denture base resins. J Prosthet Dent 2010;46(5):478-83.

\section{ABOUT THE AUTHORS}

\section{LM Ranganath}

Professor, Department of Prosthodontics, RKDF Dental College and Research Centre, Bhopal, Madhya Pradesh, India

\section{Ravindra Ganguly Keshav Shet}

Professor, RKDF Dental College and Research Centre, Bhopal Madhya Pradesh, India

\section{Rajesh AG}

Professor, Department of Conservative Dentistry and Endodontics RKDF Dental College and Research Centre, Bhopal, Madhya Pradesh India

\section{Sathish Abraham}

Professor, Department of Conservative Dentistry and Endodontics RKDF Dental College and Research Centre, Bhopal, Madhya Pradesh India

\section{CORRESPONDING AUTHOR}

LM Ranganath, Professor, Department of Prosthodontics, RKDF Dental College and Research Centre, Hoshangabad Road, Bhopal-462026 Madhya Pradesh, India, Phone: +919845056441, +919980056441 e-mail: dentique@ymail.com 